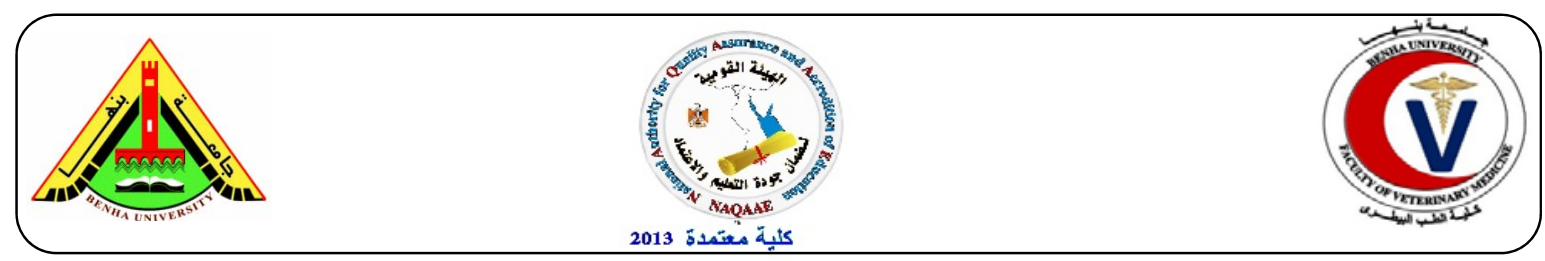

\title{
Clinico-biochemical and surgical evaluation of omaso-abomasal volvulus in cattle
}

\author{
Akraiem, $\mathbf{A}^{1}$., Kumper H. ${ }^{2}$, Doll K. ${ }^{2}$, Abd Elghany, H. ${ }^{3}$ \\ ${ }^{1}$ Department of Veterinary Medicine and Surgery, Faculty of Veterinary Medicine, Omar Al-Mukhtar University, \\ Libya. ${ }^{2}$ Clinic for Ruminants and Swine (Internal Medicine and Surgery), Justus-Liebig-University, Germany. ${ }^{3}$ \\ Department of Animal Medicine Faculty of Veterinary Medicine, Banha University - Egypt.
}

\begin{abstract}
A B S T R A C T
The aim of the present study was to determine and characterize the clinical, hematological, biochemical parameters and outcome in cows suffering from Omaso-abomasal volvulus (OAV). Animals data were obtained from medical records of 60 adult dairy cattle suffering from OAV (Clinic for Ruminants, Justus-Liebig-University, Germany). For each case, history, age, results of clinical examination, hematological and biochemical findings were recorded and analyzed. Ages of animals were between 2.3 and 8 years, (mean 4.8). Compared with the respective normal range, there were significant increases of the heart rate, hematocrit, total bilirubin, urea blood, concentrations of bicarbonate and base excess. Serum chloride and potassium were significantly decreased in the majority of cows. In this study, dehydration, metabolic alkalosis, hypochloremia, hypokalemia and circulatory insufficiency were the major common findings in cows with Omasum-abomasal volvulus. Excessive stretching of the abomasal wall and long lasting strangulations at the torsion-sites must be avoided (surgery should be performed as soon after diagnosis of AOV as possible) and correction of these conditions with aggressive intravenous fluid therapy is necessary before the surgical intervention for correction of the hematobiochemical alterations.
\end{abstract}

keywords: abomasal, volvulus, cows.

(http://www.bvmj.bu.edu.eg) $\quad$ (BVMJ-30(2): 6-11, 2016)

\section{INTRODUCTION}

$\mathrm{S}$ urgical abomasal disorders are important in dairy production. Although left displaced abomasum occurs more commonly and has a good prognosis, the prognosis may be more variable in cases of right abomasal disorders, which can be either dilated abomasum (RDA) or abomasal volvulus (AV). The AV generally has a less favorable prognosis than RDA because of various degrees of neurovascular and inflammatory damage that may occur in the abomasum (Sattler et al., 2000; Niehaus, 2008).

Abomasal displacement has a multifactorial etiology and constitutes the most common cause of surgical gastrointestinal disorders in dairy cattle (Smith, 1978; Fubini et al., 1991; Rohn et al., 2004). AV is a twisting of the stomach on the right side of the cow. The condition occurs less frequently than left displaced abomasum (Smith, 1978; Fubini et al., 1991; Rohn et al., 2004). The mortality rate for $\mathrm{AV}$ is higher than that for left displaced abomasum. When the twist of the abomasum exceeds 180 degrees (abomasal volvulus), the twine gets more contracted, strangulating the abomasal nerves and blood vessels (Fubini et al., 1991; Meylan, 1999; Sattler et al., 2000). Abomasal displacement is characterized by dehydration and metabolic alkalosis due to continuous secretion of hydrochloric acid, sodium, potassium and chloride into the abomasum (Aksoy, 1981; Simpson et al., 1985; Braun et al., 1990; Smith, 1990; Constable et al., 1992; Kumper, 1995; Geishauser et al., 1996). When the abomasal volvulus is complicated by an omasal (RDAO) or an omasal and reticular involvement (RDAOR) the success of therapy decreases to about $40 \%$ (Buchanan et al., 1991; Constable et al., 1992; Kumper, 1995; Meylan, 1999; Rohn et al., 2004). While some animals die of hypovolemic or septic shock shortly after surgical correction of RDA/AV, others survive the acute postsurgical period but develop other related problems. The most frequent postoperative complication encountered with RDA/AV is a gastrointestinal dysfunction (Meylan, 1999). The aim of this study is to determine and 
evaluate the clinical, hemato-biochemical and surgical findings of clinical cases of omasoabmasal volvulus in dairy cows.

\section{MATERIALS AND METHODS}

Sixty adult dairy cows suffering from Omaso-abomasal volvulus (OAV) were included in this study. German Black Holsteins and German Red Holsteins were the two breeds included in this study. The ages of the animals were between 2.3 and 10 years. The majority of cows were diagnosed with OAV $(\mathrm{n}=46)$ and right omasoabomasal volvulus (ROAV) $(\mathrm{n}=$ 14). Diagnosis of OAV based on clinical examination, position and direction of torsion. Type and degree of torsion were confirmed by right flank laparotomy.

For each case, history, age, results of clinical examination and hematobiochemical findings were recorded and analyzed. Animal data obtained included heart rate, respiratory rate, temperature, rumen motility, fecal quantity in rectum and filling of the rumen. Whole blood and plasma samples were collected to evaluate the hematobiochemical findings which include Hematocrit, Total bilirubin, Urea, the venous blood gas values ( $\mathrm{pH}$ value, bicarbonate content and base excess) serum levels of chloride potassium and sodium. Routine general clinical and laboratory examinations were performed from each case at the time of admission in the clinic (before the surgery). Surgery was performed according to the method described by Dirksen on the day of arrival. The surgical and survival information's were obtained from the medical records continuously. The abdominal explorations and short and long-term outcome were analyses. Owners of animals discharged from the veterinary clinic were contacted to obtain additional follow- up information regarding long-term survival and outcome.

\section{RESULTS}

\subsection{Clinical findings}

The major clinical signs were recorded in table (1). The rectal temperature varied from $37.5{ }^{\circ} \mathrm{C}$ to $40{ }^{\circ} \mathrm{C}$. The mean of rectal temperature was within the normal range in 57 (95\%) cows while, hyperthermia in 3 cows (5\%) was recorded. The heart rate varied from
60- $132 \mathrm{pbm}$. and it was significantly $(P<0.05)$ increased in 29 cows $(48.3 \%)$ and decreased in 3 cows $(5 \%)$. The mean of respiratory rate was within the normal range in 47 cows $(78.3 \%)$ while, there was significant $(\mathrm{P}<0.05)$ increase in the respiratory rate in 13 cows $(21.7 \%)$. Rumen motility was absent in 51 cows $(85 \%)$, while in 9 cows $(15 \%)$ were hypomotile with reduced strength of ruminal contraction. Fecal quantity in rectum was scanty in 49 cows $(81.6 \%)$ or absent in 11 cows $(18.3 \%)$. Rectal palpation of the dilated abomasums was available in 59 cows $(98.3 \%)$.

\subsection{Surgical findings and outcome table (2)}

The abdominal explorations revealed sever dilatation of abomasums in 43 cows $(71.7 \%)$. The torsion degree was diagnosed by $180^{\circ}$ in 45 and by $360^{\circ}$ in 14 cows; while in one case the torsion degree was more than $360^{\circ}$. Forty-eight cows (80\%) (38 cows recovered completely, 10 improved) were discharged home for further observation. Necropsy findings were only available for the cows that were not released from the clinic. Patients that died or were euthanatized in the clinic (12 cows) showed severe lesions of the abomasum, as ulcers, necrosis and abomasal impaction. six months after discharge, 34 cows $(56.7 \%)$ were at their home farm and utilized performed normally. Six of the remaining 14 cows were culled because of other diseases (fertility disorders, mastitis, claw disorders).

\subsection{Biochemical findings:}

Compared with the respective normal range values, there were significant $(p<0.05)$ increases of hematocrit $(0.46 \pm 0.1 / 11$; varied from 0.30 to $0.551 / 1)$, total bilirubin $(13.8 \pm 7.4$ $\mu \mathrm{mol} / 1$; varied from 5.3 to $36.8 \mu \mathrm{mol} / \mathrm{l})$, urea $(9.78 \pm 6.3 \mathrm{mmol} / \mathrm{l}$; varied from 2.7 to 25.8 $\mathrm{mmol} / \mathrm{l})$, blood concentrations of bicarbonate $(1.1 \pm 0.62 \mathrm{mmol} / \mathrm{l}$; varied from 18.6 to 50.9 $\mathrm{mmol} / \mathrm{l})$, and base excess $(5.75 \pm 7.03 \mathrm{mmol} / \mathrm{l}$; varied from -6.6 to $25.7 \mathrm{mmol} / \mathrm{l})$. The mean of $\mathrm{pH}$-value of venous blood $(7.39 \pm 0.07$; varied from7.22 to 7.49) and serum Sodium (135 \pm 13.1 $\mathrm{mmol} / \mathrm{l}$; varied from 128 to $145 \mathrm{mmol} / \mathrm{l}$ ) had not significant changes. The obtained data indicated significant decreases $(p<0.05)$ in serum chloride $(87 \pm 13.07$; varied from 55 to $115 \mathrm{mmol} / \mathrm{l})(60 \%$ cases$)$ and potassium (3.20 \pm 0.59 ; varied from 1.72 to $4.58 \mathrm{mmol} / \mathrm{l}$ ) in the affected cows (Table 3 ). 
Table (1) Clinical findings of omasao-abomasal volvulus $(\mathrm{N}=60)$.

\begin{tabular}{ll}
\hline Clinical parameter & Number of cases (\%) \\
\hline $\begin{array}{l}\text { Rectal temperature }{ }^{\circ} \mathrm{C} \\
\text { Normal }\left(38-39.2^{\circ} \mathrm{C}\right)\end{array}$ & $57(95 \%)$ \\
Increased & $3(5 \%)$ \\
Heart rate (beat / min); Normal $(70-90)$ & \\
Normal & $28(46.7 \%)$ \\
Low & $29(5 \%)$ \\
Increased & $3(48.3 \%)$ \\
Respiratory rate (breath / min) Normal (20-40) & \\
Normal & $47(78.3 \%)$ \\
Increased & $13(21.7 \%)$ \\
Rumen motility; Normal (2 to 3 contr. / 2min) & \\
reduced (<2 contr/2 min) & $9(15 \%)$ \\
Absent (0 contr. / 2 min) & $51(85 \%)$ \\
Fecal quantity in rectum & \\
Scanty & $49(81.6 \%)$ \\
Absent & $11(18.3 \%)$ \\
Rectal palpation of the dilated abomasum & \\
Available & $59(98.3 \%)$ \\
Not available & $1(1.7 \%)$ \\
\hline
\end{tabular}

Table (2) Surgical findings of omasao-abomasal volvulus $(\mathrm{N}=60)$.

\begin{tabular}{lc}
\hline Description & Number of cases (\%) \\
\hline Degree of torsion & $45(75 \%)$ \\
$180^{\circ}$ & $14(23.3 \%)$ \\
$360^{\circ}$ & $1(1.7 \%)$ \\
$>360^{\circ}$ & \\
Direction of the torsion & $60(100 \%)$ \\
Rotation to the left (contra clockwise) & 0 \\
Rotation to the right (clockwise) & \\
Type of torsion & $46(76.7 \%)$ \\
(OAV) & $14(23.3 \%)$ \\
ROAV) & $17(18.3 \%)$ \\
Abomasal Size & $43(71.7 \%)$ \\
Moderately dilated & \\
Severely dilated & \\
\hline
\end{tabular}

Table (3) Serum values (Mean $\pm \mathrm{SD}$ ) of some biochemical parameters of omasao-abomasal volvulus $(\mathrm{N}=60) . *(P<0.05)$.

\begin{tabular}{lccccc}
\hline \multicolumn{1}{c}{ Parameter } & Units & OAV \& ROAV & $\begin{array}{c}\text { Reference range } \\
\text { (Velden 1975) }\end{array}$ & \multicolumn{2}{c}{$\begin{array}{c}\text { No. of cases with } \\
\text { abnormal value }\end{array}$} \\
\hline Haematocrit & $1 / 1$ & $0.41 \pm 0.1^{*}$ & $0.30-0.40$ & 40 & $(66.7 \%)$ \\
Total billirubin & $\mu \mathrm{mol} / 1$ & $13.8 \pm 7.4^{*}$ & $0.9-7.0$ & 50 & $(83.3 \%)$ \\
Urea & $\mathrm{mmol} / 1$ & $9.78 \pm 6.3^{*}$ & $1.7-7.5$ & 40 & $(66.7 \%)$ \\
$\mathrm{pH}$ (blood) & value & $7.39 \pm 0.07$ & $7.36-7.44$ & 27 & $(45 \%)$ \\
Bicarbonate & $\mathrm{mmol} / 1$ & $31.5 \pm 7.73^{*}$ & $20-30$ & 26 & $(43.3 \%)$ \\
Base excess & $\mathrm{mmol} / 1$ & $5.75 \pm 7.03^{*}$ & $-3-+3$ & 40 & $(66.7 \%)$ \\
Sodium & $\mathrm{mmol} / 1$ & $135 \pm 13.1$ & $135-155$ & 19 & $(31.7 \%)$ \\
Potassium & $\mathrm{mmol} / 1$ & $3.20 \pm 0.59^{*}$ & $4-5$ & 37 & $(61.7 \%)$ \\
Chloride & $\mathrm{mmol} / 1$ & $87 \pm 13.07^{*}$ & $90-110$ & 40 & $(66.7 \%)$ \\
& & & & & \\
\hline
\end{tabular}




\section{DISCUSSION}

Displacement of the abomasum is a condition in dairy cows resulting in economic losses and reduction of animal welfare. In this study, the records of 60 cases of OAV were reviewed. The clinical examination revealed, in the majority of cows. the rectal temperature $(95 \%)$ and the respiratory rate $(78 \%)$ were within the normal range. Three cows (5\%) showed hyperthermia and a prolonged duration of the illness. Increased respiratory rate was recorded in 13 cows $(21.7 \%)$. The increased temperature values might have been due to septicemia accompanying concurrent parturition diseases, such as metritis, mastitis (Fubini et al., 1991; Constable et al., 1992). Increase of the respiratory rate was probably due to the increased pressure of the dilated abomasum on the diaphragm (Fubini et al., 1991; Meylan, 1999; Rohn et al., 2004). However, there was marked increase of the heart rate in $29(48.3 \%)$ cases and $3(5 \%)$ of the cows presented bradycardia. Increased heart rate is common, and occurs in most cases of circulatory failure, abdominal pain and metabolic alkalosis (Smith, 1978; Simpson et al., 1985; Braun et al., 1990; Goetze and Müller, 1990; Breuking, 1991; Fubini et al., 1991; Rohn et al., 2004) which associated with omasoabomasal volvulus.

Most of OAV- affected cows there is no ruminal motility in $85 \%$ or reduced motility in $15 \%$ and scanty feces in $81.7 \%$ or fecal-free rectum in $18.3 \%$, these findings are similar to those recorded by (Braun et al., 1990; Fubini et al., 1991; Meylan, 1999). The dilated abomasums were palpated rectally in 59 cows (98.3\%). The abdominal explorations revealed; $(71.7 \%)$ severe dilation of the abomasums $(71.7 \%)$. In all cows, the rotation was performed to the left (counter-clockwise, seen from rear) (Meylan, 1999).

The torsion degree ranged from $180^{\circ}(n=45)$, $360^{\circ}(n=14)$ and $450^{\circ}$ in one case. In this study, the definitions stated by (Meylan, 1999) were adopted to establish the types of volvulus. Based on the surgical findings, the Omasoabomasal volvulus (OAV) was diagnosed in 46 cows and reticulo-omaso-abomasal volvulus (ROAV) 14 cows. When the twist of the abomasum exceeds 180 degrees (abomasal volvulus), the twine gets more contracted, strangulating the abomasal nerves and blood vessels (Wallace, 1989; Meylan, 1999; Sattler et al., 2000). In the present study, the majority of cows showed metabolic alkalosis (66.7\%), dehydration $(66.7 \%)$, hypochloremia $(66.7 \%)$, hypokalemia (61.7\%), however, 4 cows showed metabolic acidosis. Subsequent occlusion of the duodenum and omasal-abomasal or reticulo-omasal junction might have lead to accumulation of abomasal fluid and metabolic alkalosis might be attributed to loss or sequestration of abomasal $\mathrm{HCl}$, and the relative excess of HCO3- (Braun U et al., 1988; Buchanan et al., 1991).

In response to dehydration-induced hypovolemia, aldosterone stimulates the kidneys to retain $\mathrm{Na}+$ and water (Smith, 1978; Simpson et al., 1985; Braun et al., 1990; Constable et al., 1991; Kumper, 1995). Chloride loss is from gastric secretions due to reflux of abomasal fluid (internal vomiting), malabsorption in the lower gastrointestinal tract, or chloride sequestration in the rumen or abomasum. Therefore, $\mathrm{HCO}_{3}{ }^{-}$is the anion which is reabsorbed with $\mathrm{Na}^{+}$, decreasing the urine $\mathrm{pH}$. Sodium (and water) can also be reabsorbed via exchange with intracellular $\mathrm{K}^{+}$ or $\mathrm{H}^{+}$. In the presence of hypokalemia, $\mathrm{K}^{+}$is unavailable for exchange. Therefore, $\mathrm{H}^{+}$ions are exchanged with $\mathrm{Na}^{+}$, creating acidic urine (Braun U et al., 1988; Braun et al., 1990; Goetze and Müller, 1990; Smith, 1990; Constable et al., 2013).

Dehydration and anaerobic metabolism due to reduced peripheral perfusion is often observed in the latter stages of abomasal volvulus (Breuking, 1991; Sattler et al., 2000). The majority of cows mobilized body fat as indicated by increased of the serum levels of total bilirubin. The high diagnostic value of total serum bilirubin (Hjortkjaer and Svendson, 1979). in cows with abomasal volvulus, may be the result of a partial bile duct obstruction (Smith, 1978; Hjortkjaer and Svendson, 1979; Fubini et al., 1991; Rohn et al., 2004).

When the twist of the abomasum exceeds $180^{\circ}$ (abomasal volvulus), the twine gets more contracted, strangulating the abomasal nerves and blood vessels (Trent, 1990; Meylan, 1999; Sattler et al., 2000). In this study, Short-term survival rate and long- term survival rate is higher than that given in previously published reports (Meylan, 1999). However, definition of outcome or duration of follow-up may be different from one study to another and making difficult comparisons. 
The most frequent postoperative complication encountered with abomasal volvulus is a gastrointestinal dysfunction (Meylan, 1999; Sattler et al., 2000; Zadnik, 2003b). All patients that died or were euthanatized in the clinic showed severe lesions of the abomasum, as ulcers, necrosis, peritonitis, omasal impaction and abomasal impaction which may be due to sequestration of the abomasal contents (Breuking and Kuiper, 1980; Braun et al., 1990). Abomasal volvulus in cattle is characterized by rotation of the proximal duodenum, abomasum, and omasum. The mortality rate for abomasal volvulus is higher than that for displaced abomasum when the abomasal volvulus is complicated by an omasal or an omasal and reticular involvement the success of therapy decreases to about $40 \%$ (Kuiper, 1980; Meylan, 1999).

\section{Conclusion and recommendations}

Dehydration, metabolic alkalosis, hypochloremia, hypokalemia and circulatory insufficiency are the major common findings in cows with abomasal volvulus. However, some animals die of hypovolemic or septic shock shortly after surgical correction of OAV. Excessive stretching of the abomasal wall and long lasting strangulations at the torsion-sites must be prevented (surgery should be performed as soon after diagnosis as possible) and according to the available clinicolaboratory alterations, associated with OAV, correction of these conditions with aggressive intravenous fluid therapy containing potassium chloride and correction of alkalemia and dehydration is recommended.

\section{REFERENCES}

Aksoy, G., 1981. Untersuchungen des Labmagen- und Pansensaftes, des Blutserums sowie des roten Blutbildes bei gesunden und bei an Labmagenverlagerung erkrankten Rindern (mit besonderer Berucksichtigung eines etwaigen Refluxes von Labmageninhalt in dieVormagen). . Tierarztl. Umschau 37: 640-647.

Braun U, Eicher R, V., B., 1988. Inneres Erbrechen beim Rind, Untersuchungen über das abomasale Refluxsyndrom bei verschiedenen Erkrankungen des Verdauungsapparates. Schweiz Arch Tierheilk 130: 225 - 236.

Braun, U., Steiner, A., Kaegi, B., 1990. Clinical, haematological and biochemical findings and the results of treatment in cattle with acute functional pyloric stenosis. Vet. Rec. 126: 107 110.

Breuking, H.J., 1991. Abomasal displacement, etiology, pathogenesis, treatment and prevention. Bovine practitioner. 26, 148.

Breuking, H.J., Kuiper, R., 1980. Digestive disorders following obstruction of flow of ingesta through the abomasum and small intestine. Bovine Practitioner 15: 139-143.

Buchanan, M., Cousin, D.A., MacDonald, N.M., Armour, D., 1991. Medical treatment of right-sided dilatation of the abomasum in cows. Vet. Rec 129: 111112.

Constable, P., Grunberg, W., Staufenbiel, R., Stampfli, H.R., 2013. Clinicopathologic variables associated with hypokalemia in lactating dairy cows with abomasal displacement or volvulus. Journal of the American Veterinary Medical Association 242: 826-835.

Constable, P.D., Jean, G.S., Hull, B.L., Rings, M.R., Hosffsis, G.F., 1991. Prognostic value of surgical post-operative findings in cattle. Am.Vet. Med. Assoc 198: 20772085.

Constable, P.D., Miller, G.Y., Hoffsis, G.F., 1992. Risk factors for abomasal volvulus and leftabomasal displacement in cattle. Am. J. Vet. Res 53: 1184-1192.

Fubini, S.L., Grohan, Y.T., Smith, F.D., 1991. Right displacement of the abomasum and abomasal volvulus in dairy cows: 458 cases (1980-1987). J. Am. Vet. Med. Assoc. 198: 460-464.

Geishauser, T., Reiche, D., Seeh, C., Thunker, B., Verwohlt, S., Failing, K., 1996. pH, Natrium, Kalium, Magnesium, Kalzium, Phosphat und Chlorid im Pansen- und Labmageninhalt von Kuhenmit Labmagenverlagerung. . Dtsch. Tierarztl. Wschr 103: 16-20.

Goetze, L., Müller, M., 1990. The therapy of hypovolemic shock in cows with rightsided abomasaldisplacement. Zentralbl Veterinarmed A 37: 300-309. 
Hjortkjaer, R., Svendson, K., 1979. Right abomasal displacement in dairy cows. Clinical, clinical-chemical and hemodynamic findings with special reference to prognosis and circulatory disturbance. Nord. Vet. Med 31: 1-28.

Kuiper, R., 1980. Bomasal reflux in cattle. Utrecht University, Faculty of Veterinary Medicine, Dissertation.

Kumper, H., 1995. Die rechtsseitige Labmagenverlagerung des Rindes.1.Teil: Entstehungsweise, klinischer Verlauf und Prognose. Tierarztl. Praxis 23: 351359.

Meylan, M., 1999. Prognostische Indikatoren bei Labmagenverlagerung und -torsion nach rechts. Schweiz. . Arch. Tierheilk. 141: 413-418.

Niehaus, A.J., 2008. Surgery of the abomasum. The Veterinary clinics of North America. Food animal practice 24: 349-358, viii.

Rohn, M., Tenhagen, B.A., Hofmann, W., 2004. Survival of dairy cows after surgery to correct abomasal displacement: 2. Association of clinical and laboratory parameters with survival in cows with left abomasal displacement. . J.Vet. Med. 51: 300-305.

Sattler, N., Fecteau, G., Helie, P., Lapointe, J.M., Chouinard, L., Babkine, M., Desrochers, A., Couture, Y., Dubreuil,
P., 2000. Etiology, forms, and prognosis of gastrointestinal dysfunction resembling vagal indigestion occuring after surgical correction of right abomasal displacement. Can Vet J 41: 777-785.

Simpson, D.L., Erb, H.N., Smith, D.F., 1985. Base excess as a prognostic and diagnostic indicator in cows with abomasal volvulus versus right displacement of the abomasum. . Am. J. Vet. Res. 46: 796-797.

Smith, B.P., 1990. Large Animal Internal Medicine. The C.V. Mosby Company, 11830 West line Industrial Drive, St. Louis, Missouri., 63146,.

Smith, D.F., 1978. Right side torsion of the abomasum in dairy cows, classification of severity and valuation of outcome. J. Am. Vet. Med. Assoc. 173: 108-111.

Trent, A.M., 1990. Surgery of the bovine abomasum. Vet. Clin. N. Am./FAP 6: 399 - 448.

Wallace, C.E., 1989. Reticulo,omasal,abomasal volvulus in dairy cows. Bovine Practitoner 24: 74-76.

Zadnik, T., 2003b. A comparative study of the hematobiochemical parameters between clinically healthy cows and cows with displacement of the abomasum. Acta Veterinaria (Beograd) 53: 297-309. 